\title{
TBX6, LHX1 and copy number variations in the complex genetics of Müllerian aplasia
}

\author{
Maria Sandbacka ${ }^{1,2}$, Hannele Laivuori ${ }^{2,3}$, Érika Freitas ${ }^{4}$, Mervi Halttunen ${ }^{3}$, Varpu Jokimaa ${ }^{5}$, Laure Morin-Papunen ${ }^{6}$, \\ Carla Rosenberg ${ }^{4}$ and Kristiina Aittomäki, ${ }^{1, *}$
}

\begin{abstract}
Background: Müllerian aplasia (MA) is a congenital disorder of the female reproductive tract with absence of uterus and vagina with paramount impact on a woman's life. Despite intense research, no major genes have been found to explain the complex genetic etiology.

Methods and Results: We have used several genetic methods to study 112 patients with MA. aCGH identified CNVs in 8/50 patients (16\%), including 16p11.2 and 17q12 deletions previously associated with MA. Subsequently, another four patients were shown to carry the $\sim 0.53 \mathrm{Mb}$ deletion in 16p11.2. More importantly, sequencing of TBX6, residing within $16 \mathrm{p} 11.2$, revealed two patients carrying a splice site mutation. Two previously reported TBX6 variants in exon 4 and 6 were shown to have a significantly higher frequency in patients ( $8 \%$ and 5\%, respectively) than in controls (2\% each). We also sequenced $L H X 1$ and found three apparently pathogenic missense variants in 5/112 patients. Altogether, we identified either CNVs or variations in TBX6 or LHX1 in 30/112 (26.8\%) MA patients. CNVs were found in 12/112 (10.7\%), patients, novel variants in TBX6 or LHX1 in 7/112 (6.3\%), and rare variants in TBX6 in 15/112 (13.4\%) patients. Furthermore, four of our patients (4/112, 3.6\%) were shown to carry variants in both TBX6 and $L H X 1$ or a CNV in combination with TBX6 variants lending support to the complex genetic etiology of MA.
\end{abstract}

Conclusions: We have identified TBX6 as a new gene associated with MA. Our results also support the relevance of $\angle H X 1$ and $C N V$ s in the development of this congenital malformation.

\section{Background}

Müllerian aplasia (MA) is a rare disorder of the female reproductive tract presenting as congenital loss of a functional uterus and vagina. MA is commonly diagnosed in adolescent females due to lack of menstruation and has a large impact on a woman's life. Inability of normal sex life prior to treatment and infertility combined with psychosocial problems make it one of the difficult fertility disorders diagnosed in young females. MA is also referred to as MURCS association (Müllerian duct aplasia, Renal dysplasia and Cervical Somite anomalies [MIM 601076]), because renal and skeletal malformations are associated with the disorder. Despite MA, the patients have a normal female karyotype and secondary sexual characteristics [1].

\footnotetext{
* Correspondence: kristiina.aittomaki@hus.fi

'Folkhälsan Institute of Genetics, Helsinki, Finland

${ }^{7}$ Department of Clinical Genetics, HUSLAB, Helsinki University Central Hospital, Helsinki, Finland

Full list of author information is available at the end of the article
}

The incidence is estimated to be at least one in 5000 according to a population-based study in Finland [2].

During vertebrate embryogenesis, the female reproductive tract forms as a part of the urogenital system derived from the intermediate mesoderm of the developing embryo. The urogenital system encompasses the kidneys, gonads and the urinary and reproductive tracts. The female reproductive tract primarily develops from the Müllerian ducts (MD), which form as an invagination of the coelomic epithelium and further develop into the upper two-thirds of the vagina, the uterus and the Fallopian tubes $[3,4]$.

Most patients with MA have the Mayer-RokitanskyKüster-Hauser (MRKH [MIM 277000]) phenotype with presence of small remnants of the uterus and with unilateral/bilateral Fallopian tubes. A small group of patients are reported with complete loss of Müllerian derivatives, called total Müllerian aplasia [1,2].

The genetic background of MA has been intensively studied. The anti-Müllerian hormone $(A M H)$, essential

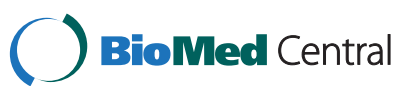

(c) 2013 Sandbacka et al.; licensee BioMed Central Ltd. This is an Open Access article distributed under the terms of the Creative Commons Attribution License (http://creativecommons.org/licenses/by/2.0), which permits unrestricted use, distribution, and reproduction in any medium, provided the original work is properly cited. 
for $\mathrm{MD}$ regression during male differentiation, its receptor AMHR2 and members of the HOXA and WNT gene families were primarily investigated in MA patients, but no mutations were found [5-12]. More recently mutations in wingless-type MMTV integration site family, member 4 (WNT4) and the LIM homeobox 1 (LHX1), have been reported to be causative of MA [13-18]. However, WNT4 defects occur in MA patients with hyperandrogenism not usually associated with the syndrome [13-16]. The $L H X 1$ defects were reported in patients with $\mathrm{MRKH}$, the major clinical phenotype of MA, but only in two cases thus far $[17,18]$. The mutant mouse model for LHX1 (Lim1-/-) lacks uterus and oviducts, but has normal ovaries coinciding with MA phenotype in humans [19]. Recent mutation screening efforts in a small number of MA patients in other genes involved in the development of the $\mathrm{MD}$, namely $R A R G$, RXRA [20], CTNNB1 [21], PBX1 [22], PAX2 [23], DLGH1 and LAMC1 [24] have all been negative. The cause of MA is therefore still unknown for the vast majority of the patients.

By copy number analysis, several candidate regions have been implicated in MA [17,20,25-29]. Of these, most promising are regions on $16 \mathrm{p} 11.2$ and $17 \mathrm{q} 12$. The $17 q 12$ region includes $L H X 1$ and another candidate gene, $H N F 1 B$. HNF1B has been associated with genital malformations, diabetes and renal cysts [30], but no mutations in MA patients have been identified to date [28], [18]. In the 16p11.2 region, deletions were recently reported in four patients with MA [29]. Deletions in this region have previously been associated with autism $[31,32]$, developmental delay [33] and obesity [34], while duplications have been associated with autism [32], developmental delay [33] and schizophrenia [35]. The region includes approximately 26 genes with at least one gene with known function in mesodermal development, the T-box gene TBX6 [36]. Here, we report results of CNV analysis and screening of TBX6 and $L H X 1$ in 112 patients with MA, and suggest a role also for TBX6 in the complex genetics of MA, and therefore in the development of the female reproductive system.

\section{Patients and methods}

One-hundred and ten Finnish and two foreign patients originating from Russia and Middle East with a wellcharacterized MA phenotype were recruited to the study as previously described [37]. The patients had not been found to have symptoms or features of other syndromes. Two-hundred women with at least one normal pregnancy served as controls. Informed consent was obtained from all patients and controls before recruitment. The study protocol has been approved by the Ethics Committee of the Department of Obstetrics and Gynecology, Helsinki
University Central Hospital, Finland, and the Finnish Ministry of Social Affairs and Health.

\section{Sample preparation}

DNA from the patients and controls was extracted from peripheral blood samples using the Puregene DNA Isolation Kit (Gentra Systems, Minneapolis, MN, USA), or by the phenol-chloroform method. The quality and quantity of DNA was analyzed by NanoDrop ND-1000 spectrophotometer (Thermo Fisher Scientific, Waltham, MA, USA).

\section{Array Comparative Genomic Hybridization (aCGH)}

Fifty Finnish patients, in whom detailed phenotypic data had been obtained by laparoscopy, were selected for the aCGH analysis, which was performed on a $180 \mathrm{~K}$ platform (Oxford Gene Technology, Yarnton, Oxford, UK). Briefly, samples were labeled with Cy3-and Cy5deoxycytidine triphosphates by random priming. Purification, hybridization and washing were carried out as recommended by the manufacturer. Scanned images of the arrays were processed using Feature Extraction software (Agilent Technologies, Santa Clara, CA, USA). Genomic Workbench software (Agilent Technologies) was used for calling DNA copy number variations (CNVs) using the aberration detection statistical algorithm ADM-2, and sensitivity threshold 6.7. Duplication or deletion of a genomic segment was considered, when the $\log 2$ ratio of the Test/Reference intensities of a given region encompassing at least three probes was $>0.3$ or $<-0.3$, respectively. Detected CNVs were compared to CNV data documented in the Database of Genomic Variants (DGV) [38].

\section{Multiplex ligation-dependent probe amplification (MLPA)}

The MLPA method was used to study the 112 patients for larger deletions or duplications within TBX6. One hundred control samples were also investigated with the method. Synthetic MLPA probes (Additional file 1: Table S1) covering each of the coding exons of TBX6 (exons 2-9, TBX6-001 transcript, Ensembl genome database hg19/GRCh37) [39], the non-coding exon 1, the 3' UTR region and a presumptive TBX6 promotor region upstream of exon 1 identified by CpG Plot [40] and CpG Island Searcher [41] were designed according to the manual Designing synthetic MLPA Probes (MRC-Holland, Amsterdam, the Netherlands). The specificity of the probe sequences were checked using the UCSC Genome Browser (GRCh37/hg19) [42], the RaWProbe Version $0.15 \beta$ program [43] and Mfold [44]. To enable even spreading of the probe sizes and compatibility with the P300 Human reference probemix (MRCHolland), the lengths of nine of the eleven probes were adjusted using non-hybridizing stuffer fragments. The 
final sizes of the synthetic probes including the universal primers and a stuffer sequence were designed to range between 96 bp and 136 bp (IDT, San Jose, CA, USA).

The MLPA reactions were performed according to the manufacturer's recommendations. In short, $200 \mathrm{ng}$ of DNA was denatured and incubated with a mix including $1 \mu \mathrm{M}$ of each of MLPA synthetic oligos and the P300 Human reference probemix for $16-18 \mathrm{~h}$ in $60^{\circ} \mathrm{C}$. The probes were ligated to the DNA and amplified by PCR. Thereafter, the PCR products were visualized on an agarose gel (1.5\%, Bioline, London, UK), appropriately diluted and combined with $1 \%$ formamide (Applied Biosystems) and GeneScan ${ }^{\text {Tm }}-500$ LIZ $^{\text {mo }}$ size standard (Applied Biosystems). The products were separated by capillary electrophoresis on an ABI3730XL DNA Analyzer (Applied Biosystems). The results were analyzed by GeneMapper software version 4.0 (Applied Biosystems) and verified by the following calculation. For each sample, each peak area was divided by the sum of all peak areas (derived from the 11 synthetic TBX6 probe areas plus the 17 reference peak areas from the P300 Human reference probemix). Each quotient was further divided by the peak area of the reference sample. A result $\leq 0.7$ or $\geq 1.3$ was taken as suggestive for a deletion or duplication, respectively. All aberrant results were confirmed by a second independent MLPA analysis and deletions of the entire gene with SNP genotyping.

\section{Validation of aCGH and MLPA findings}

High-throughput genotyping was performed using the Human Omni2.5-8 BeadChip v1.0 (Illumina, San Diego, CA, USA) capturing about 2.4 million markers to confirm the genomic alterations found by aCGH and MLPA. Data analyses were performed using GenomeStudio V2011.1 (Illumina). In addition, quantitative PCR (qPCR) was used to confirm six of the deletions and duplications detected by aCGH using the SYBR Green system (Roche Applied Science, Indianapolis, IN, USA) on a 7500 Fast Real-Time PCR System apparatus (Applied Biosystems, Foster City, CA, USA). We used six of the healthy Finnish female controls for copy number calibration, and the qPCR values for the GAPDH and HPRT for normalization. All samples were run in triplicate, and the data was analyzed with Microsoft Excel software (Microsoft Corp, Redmond, WA, USA) using the comparative $\Delta \Delta^{\mathrm{C}}$ t cycle threshold method (Applied Biosystems), which assumes that the calibrator DNA has two copies of the control genes.

\section{PCR and Sanger sequencing}

The coding exons and exon-intron boundaries of TBX6 (exons 2-9, TBX6-001 transcript, Ensemble genome database hg19/GRCh37) [39] were studied in 112 patients and 200 controls by Sanger sequencing. The PCR primers were designed using ExonPrimer [45] and Primer3 v. 0.4.0 [46]. The PCR was performed under standard conditions. The products were visualized by gel electrophoresis and subjected to sequencing in an ABI3730xl DNA Analyzer (Applied Biosystems) and analyzed by Sequencher 5.0 (Gene Codes, Ann Arbor, MI, USA). Likewise, all coding exons and exon-intron boundaries of LHX1 (exons 1-5, LHX1-001 transcript, Ensemble genome database hg19/GRCh37) [39] were studied in the patients and 150 controls using primers designed by Primer3 v. 0.4.0 [46] and standard PCR reactions. Variants in the coding region of $L H X 1$ were sequenced in altogether 180 controls.

\section{RT-PCR}

Peripheral blood was drawn from three patients and three controls using the PAXgene Blood RNA Tube (PreAnalytiX Gmbh, Hombrechtikon, Switzerland) and RNA was subsequently extracted by the PAXGene RNA Kit (Qiagen, Hilden, Germany) according to the recommended protocol. The extracted RNA was further treated with DNA-free kit (Applied Biosystems) to remove genomic DNA (gDNA). cDNA synthesis was done using High capacity cDNA reverse transcriptase kit (Applied Biosystems) in a final volume of $20 \mu \mathrm{l}$ according to the manufacturer's recommendations. RT-PCR was performed using DreamTaq PCR master mix (2x) (Thermo Scientific, Walthem, MA, USA), primers designed for exon 4 (5' TACATTCACCCCGACTCTCC $\left.3^{\prime}\right)$ and exon 6 (5' TGGCTGCAATCTTCAGTTGT 3') by Primer3 v. 0.4.0 [46] and a touchdown thermocycling PCR program with annealing temperatures from $67^{\circ} \mathrm{C}$ to $55^{\circ} \mathrm{C}$ and the products were visualized by gel electrophoresis.

\section{Statistics}

Differences in SNP allele frequency between patients and controls were calculated using the non-parametric Mann-Whitney-U test (PASW Statistics 18, SPSS, Chicago, IL, USA) using Bonferroni correction for multiple testing.

\section{Prediction programs}

In silico analyses of genomic variants were performed using MutationTaster [47], PON-P [48] including PhDSNP 2.0.6, PolyPhen 2.0.22, SIFT 4.0.3, SNAP 1.0.8 and I-Mutant 3.0.6 programs used for analysis, SpliceMan [49], SplicePort [50] and Human Splicing Finder [51] software programs.

\section{Results}

Initially, we chose 50 patients for copy number analysis using aCGH and identified nine CNVs in eight (16\%) of them (Table 1). Two of the identified CNVs have been previously reported in MA, namely deletions on $16 \mathrm{p} 11.2$ 
Table 1 Summary of aCGH results

\begin{tabular}{|c|c|c|c|c|c|c|}
\hline Locus & $\begin{array}{l}\text { Patient } \\
\text { ID }\end{array}$ & Size & CNV & Location & Genes within CNV & $\begin{array}{l}\text { Confirmation } \\
\text { method }\end{array}$ \\
\hline $5 p 14.3$ & 28 & $1.6 \mathrm{Mb}$ & Del & $\begin{array}{l}\text { 5:18822021- } \\
20417776\end{array}$ & $\mathrm{CDH} 18$ & $\begin{array}{l}\text { SNP array, } \\
\text { qPCR }\end{array}$ \\
\hline $9 q 21.13$ & 3 & $95 \mathrm{~Kb}$ & Del & $\begin{array}{l}\text { 9:74296070- } \\
74391713\end{array}$ & TMEM2 & SNP array \\
\hline $11 q 13.4$ & 2 & $54 \mathrm{~Kb}$ & Del & $\begin{array}{l}11: 73584463- \\
73638725\end{array}$ & $\mathrm{CHCHD8,} \mathrm{PAAF1}$ & $\begin{array}{l}\text { SNP array, } \\
\text { qPCR }\end{array}$ \\
\hline $15 q 26.1$ & 4 & $96 \mathrm{~Kb}$ & Del & $\begin{array}{l}\text { 15:90883372- } \\
90979449\end{array}$ & ZNF774, IQGAP1 & $\begin{array}{l}\text { SNP array, } \\
\text { qPCR }\end{array}$ \\
\hline $16 p 11.2$ & 69 & $0.53 \mathrm{Mb}$ & Del & $\begin{array}{l}16: 29656457- \\
30190734\end{array}$ & $\begin{array}{l}\text { SPN, QPRT, C16orf54, MAZ, PRRT2, C16orf53, MVP, CDIPT, LOC440356, SEZ6L2, ASPHD1, KCTD13, TMEM219, TAOK2, HIRIP3, } \\
\text { INO80E, DOC2A, C16orf92, FAM57B, ALDOA, PPP4C, TBX6, YPEL3, GDPD3, MAPK3, LOC100271831 }\end{array}$ & SNP array \\
\hline $16 p 13.3$ & 42 & $143 \mathrm{~Kb}$ & Del & $\begin{array}{l}16: 6213403- \\
6356820\end{array}$ & A2BP1 & $\begin{array}{l}\text { SNP array, } \\
\text { QPCR }\end{array}$ \\
\hline $17 q 12$ & 24 & $1.7 \mathrm{Mb}$ & Del & $\begin{array}{l}17: 31584620- \\
33353268^{\mathrm{a}}\end{array}$ & $\begin{array}{l}\text { TBC1D3C, CCL3L1, CCL3L3, CCL4L2, CCL4L1, TBC1D3H, TBC1D3C, TBC1D3G, ZNHIT3, MYO19, PIGW, GGNBP2, DHRS11, MRM1, } \\
\text { LHX1, AATF, ACACA, C17orf78, TADA2L, DUSP14, AP1GBP1, DDX52, HNF1B, LOC284100 }\end{array}$ & SNP array \\
\hline $19 \mathrm{q} 13.11^{\mathrm{b}}$ & 49 & $194 \mathrm{~Kb}$ & Dupl & $\begin{array}{l}\text { 19:33532490- } \\
33727077\end{array}$ & RHPN2, GPATCH1, WDR88, LRP3, SLC7A10 & $\begin{array}{l}\text { SNP array, } \\
\text { qPCR }\end{array}$ \\
\hline $19 q 13.12^{b}$ & 49 & $0.6 \mathrm{Mb}$ & Dupl & $\begin{array}{l}19: 35731695- \\
36309487\end{array}$ & $\begin{array}{l}\text { LSR, USF2, HAMP, MAG, CD22, FFAR1, FFAR3, FFAR2, KRTDAP, DMKN, SBSN, GAPDHS, TMEM147, ATP4A, HAUS5, RBM42, ETV2, } \\
\text { COX6B1, UPK1A, ZBTB32, MLL4, TMEM149, U2AF1L4, PSENEN, LIN37, HSPB6, C19orf55, SNX26, PRODH2 }\end{array}$ & $\begin{array}{l}\text { SNP array, } \\
\text { qPCR }\end{array}$ \\
\hline
\end{tabular}

aocation according to UCSC genome database hg18.

${ }^{b}$ likely to include non-duplicated regions, possibly due to other chromosomal rearrangements e.g. inversions within the region or non-functional aCGH probes.

$\mathrm{CNV}=$ copy number variations, $\mathrm{Del}=$ deletion, $\mathrm{Dupl}=$ duplication

Location according to UCSC genome database hg19 [42]. 
[29] and 17q12 [27-29], and we therefore decided to further investigate two interesting MA candidate genes within these two regions, namely TBX6 and $L H X 1$.

DNA from 112 MA patients was Sanger sequenced for the entire coding region and the exon-intron boundaries of TBX6 (exons 2-9, RefSeq NM_004608.3). We found a novel heterozygous splice site mutation c.622-2A $>\mathrm{T}$ (g.30100162 T>A) in two patients (Figure 1). The mutation was not found by sequencing 200 Finnish healthy females, in dbSNP [52], in 1000 Genomes database [53], or in cohort data comprising of 1532 alleles of Finnish ancestry (A-P Sarin and A. Palotie, personal communication). In Exome Variant Server (EVS, [February, 2013 accessed]) [54], where >12000 alleles of African American and European American ancestry have been sequenced for TBX6, no allele with this variant was reported.

The mutation (c.622-2A $>\mathrm{T}$ ) is situated in the canonical sequence of the highly conserved splice acceptor site (AG) for exon 5 (Figure 2). MutationTaster [47], SplicePort [50] and Human Splicing Finder [51] prediction programs all indicate that the mutation causes loss of the functional acceptor site while the SpliceMan predictor program [49] gives a prediction score of $69 \%$ for the likelihood of the mutation to disrupt splicing. The loss of the splice acceptor site is likely to result in skipping of exon 5 or the use of cryptic splice sites. The c.622-2A $>\mathrm{T}$ mutation resides within the highly conserved DNA-binding domain, the T-box, of the protein (aa 100-273, encoded from the 3'end of exon 3 to the 3' end of exon 6) (Figure 2). RT-PCR revealed presence of at least three different transcripts ranging from about 270 to $480 \mathrm{~kb}$ in size, all present in both patient and control samples.

In addition, we found six TBX6 variants, all previously reported in dbSNP [52] (Table 2). Noteworthy is that the exonic missense variants in exon 4 (rs56098093; g.30100401C>T; p.Gly162Ser) and exon 6 (rs201231713; g.30099890C > T; p.Arg272Gln) were found in a higher frequency in patients compared to healthy females. The minor allele frequency (MAF) for rs56098093 was 8.0\% for the patients and $2 \%$ for the controls and MAF for rs 201231713 was $5.8 \%$ for the patients and $2 \%$ for the controls. The differences were statistically significant $(P$-value 0.0021 for rs56098093 and 0.0002 for rs201231713), after a stringent Bonferroni correction for multiple testing $(P$-value $/ 2<0.05)$. Interestingly, two Finnish MA patients were homozygous for both variants (AA and AA, respectively) while none of the 200 sequenced controls were homozygous for either of the variants. In the Finnish cohort data of 1532 alleles, the frequencies of the variants were $0.5 \%$ (exon 4 ) and $0.7 \%$ (exon 6), respectively (A-P Sarin and A. Palotie, personal communication). Both variants are situated within the highly conserved DNA-binding T-box region of the gene (Figure 2). MutationTaster [47] predicts both variants as disease causing with loss of the DNA-binding region of the gene. PON-P [48] predicts both variants as pathogenic with a probability of pathogenicity scores of 0.81 (Gly162Ser) and 1 (Arg272Gln), respectively.

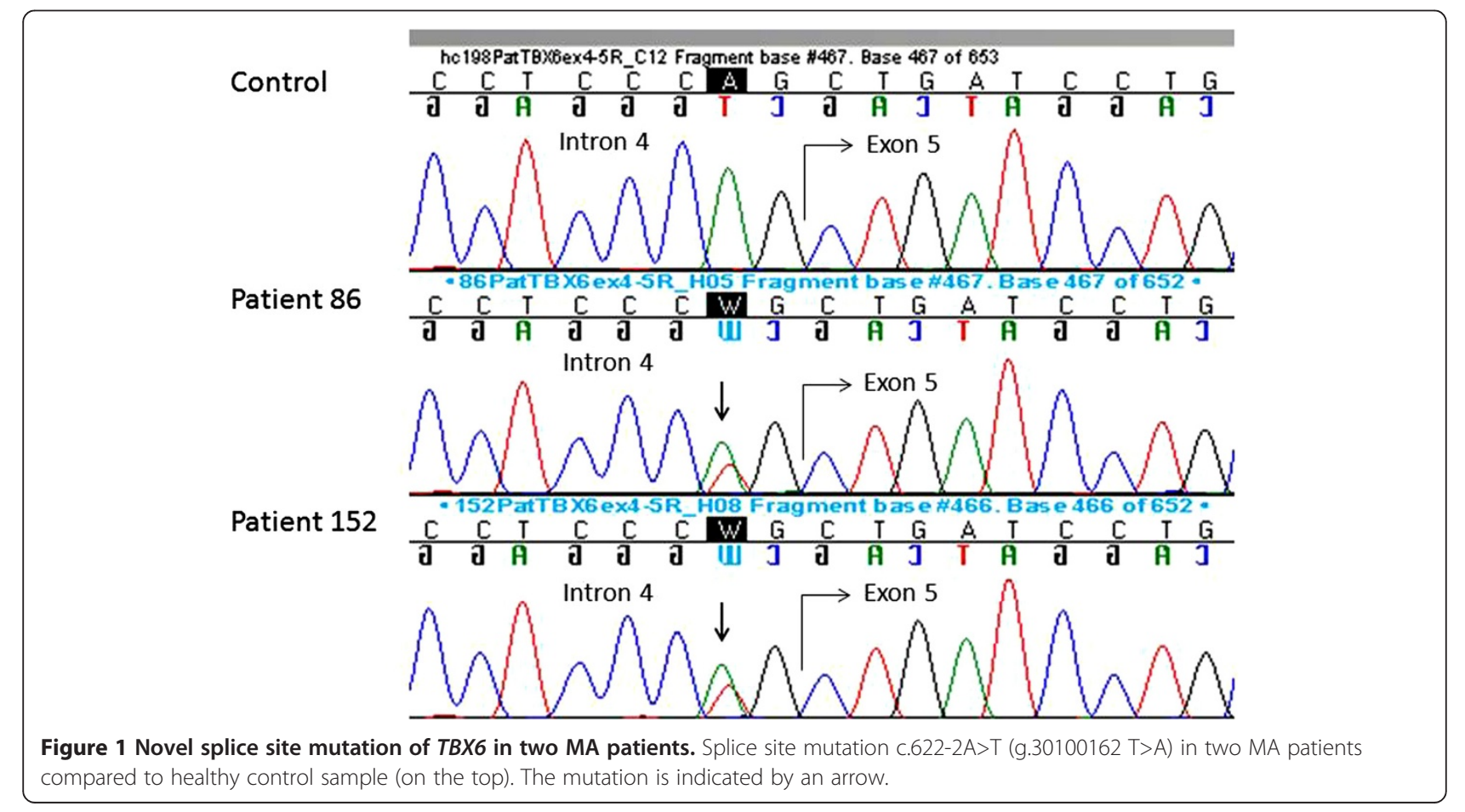




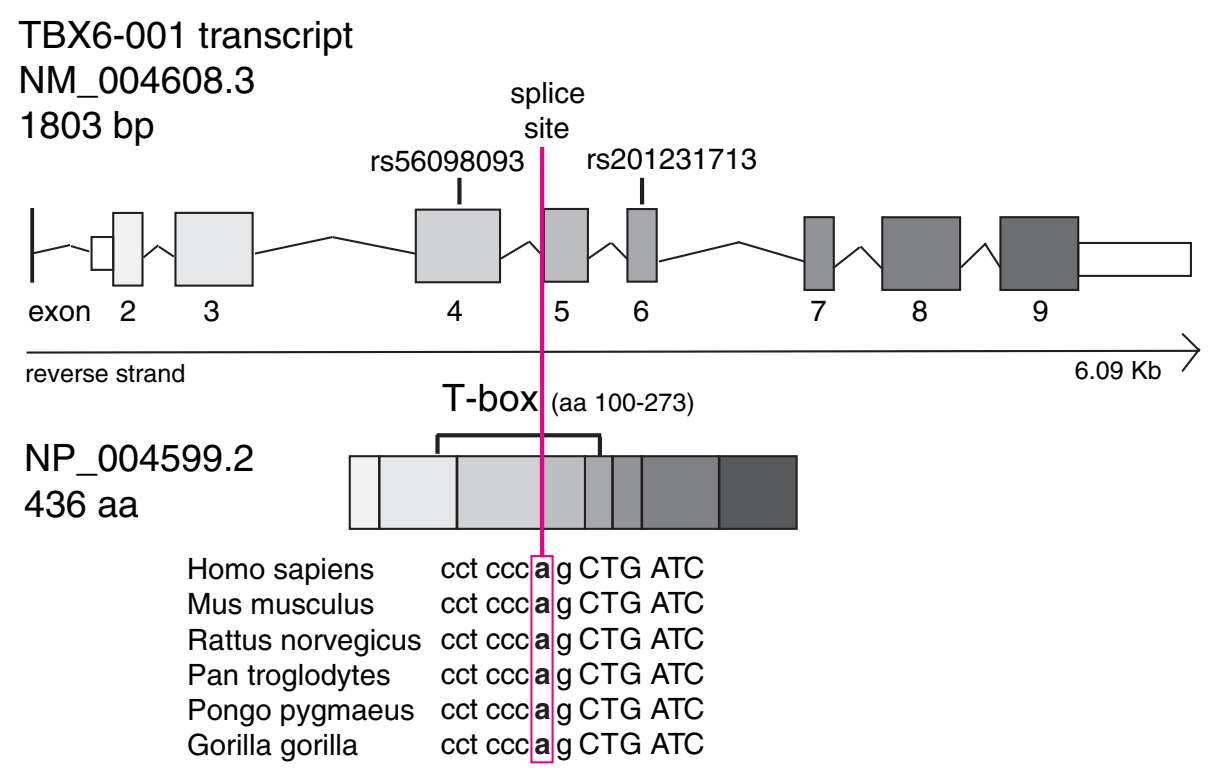

Figure 2 Schematic view of TBX6. A schematic view of TBX6 on genomic and protein level with indication of rare variants (rs56098093 and rs201231713) and the splice site mutation site (g.30100162 T>A, c.622-2A>T in violet brackets and a line) and its conservation among species.

MLPA analysis of TBX6 showed heterozygous deletion of the entire TBX6 in five out of 112 (4.5\%) patients, including the patient with $16 \mathrm{p} 11.2$ deletion found by aCGH (Figure 3). The peak area-based calculations indicated that these patients have a loss of one copy for all eleven TBX6 probes (value approximately 0.7) compared to the reference with two gene copies (value 1.0) and to the 100 healthy female controls. To delineate further the nine CNVs found by aCGH and the TBX6 deletions found by MLPA, these patients were also studied by SNP genotyping (HumanOmni2.5-8, Illumina). The heterozygous TBX6 deletions found by MLPA were shown to embrace not only TBX6, but the same $0.53 \mathrm{~Kb}$ deletion on $16 \mathrm{p} 11.2$, which was initially detected by aCGH in patient 69, in all five patients (Figure 4).

By sequencing the entire coding region and the exonintron boundaries of $L H X 1$, we found altogether five patients with novel variants in the gene (Figure 5). One patient had a missense variant (g.35295505G>C; p. Cys4Ser) in exon 1, three patients had the same missense variant in ex 5 (g.35300142C>A; p.Pro312His) and one patient had another missense variant in ex 5 (g.35300202C>G; p.Arg332Pro) (Table 3). None of the variants are reported in dbSNP [52], 1000 Genomes database [53] or EVS, except Arg332Pro, which was found in 1/12783 alleles in EVS. MutationTaster [47] predicts all three missense variants as disease causing. The program predicts the Cys4Ser variant to cause loss of the LIM zinc-binding 1 domain (aa 4-54) of the gene. PON-P [48] predicts Cys4Ser as unclassified with a probability of pathogenicity score 0.75 , Pro312His and
Arg332Pro as neutral with probability of pathogenicity scores of 0.03 and 0.01 , respectively.

A flow chart summarizing the main results and methods is shown in Figure 6.

\section{Discussion}

We report here the results of genetic studies on Müllerian aplasia, namely, results of TBX6 and LHX1 mutation screening in $112 \mathrm{MA}$ patients and CNV analysis in a subset of them.

Sequencing of TBX6 (located in 16p11.2) revealed a splice mutation in two patients and rare missense variants in 15 patients (13.4\%). TBX6 is a transcription factor that functions in early embryogenesis. It resides on the minus strand with a full-length transcript of $1806 \mathrm{bp}$, encoding a 436 aminoacid protein (NP_004599.2). TBX6 is a member of a phylogenetically well-conserved T-box gene family, where all members share the similar N-terminal DNA-binding domain, the T-box [55]. We identified a c.622-2A $>\mathrm{T}$ splice site mutation in two patients (one with MRKH and the other with total MA and with ovarian aplasia) and a rare homozygous missense variant in exon 4 and exon 6 in two patients. The splice site mutation is situated in the highly conserved splice acceptor site (AG) of exon 5. According to the in silico prediction programs, the mutation is likely to decrease correct splicing of exon 5, which is located in the highly conserved DNA-binding T-box, or result in use of cryptic splice sites. To investigate the consequences of this mutation on mRNA level, we extracted RNA from whole blood, which was available 
Table 2 Variants of TBX6 with allele frequencies

\begin{tabular}{|c|c|c|c|c|}
\hline Variant $^{\mathrm{a}}$ & rs number $^{b}$ & Location in $T B X 6$ & Genotype of patients ${ }^{c}$ & Genotype of controls \\
\hline Predicted change & & & $\mathrm{N}=112$ & $\mathrm{~N}=\mathbf{2 0 0}$ \\
\hline g.30102391G>A & rs112565029 & intron 2 & CC: 107 (95.5\%) & CC: 187 (93.5\%) \\
\hline \multirow[t]{2}{*}{ c. $118+6 C>T$} & & & CT: 5 (4.5\%) & CT: 13 (6.5\%) \\
\hline & & & ТТ: 0 (0\%) & Tा: 0 (0\%) \\
\hline g. $30100402 G>A$ & rs147485102 & exon 4 & CC: 111 (99.1\%) & CC: 198 (99\%) \\
\hline \multirow[t]{2}{*}{ p.Ser161= } & & & CT: 1 (0.9\%) & CT: 2 (1\%) \\
\hline & & & Т: 0 (0\%) & TТ: 0 (0\%) \\
\hline g. $30100401 \mathrm{C}>\mathrm{T}$ & rs56098093 & exon 4 & GG: 97 (86.6\%) & GG: 192 (96\%) \\
\hline \multirow[t]{2}{*}{ p.Gly162Ser } & & & GA: 12 (10.7\%) & GA: 8 (4\%) \\
\hline & & & AA: $3(2.7 \%)$ & AA: $0(0 \%)$ \\
\hline g.30100162 T>A & - & intron 4 & AA: 11 (98.2\%) & AA: $200(100 \%)$ \\
\hline \multirow[t]{2}{*}{ c. $622-2 \mathrm{~A}>\mathrm{T}$} & & & AT: 2 (1.8\%) & AT: $0(0 \%)$ \\
\hline & & & TT: 0 (0\%) & TT: 0 (0\%) \\
\hline g. $30099890 \mathrm{C}>\mathrm{T}$ & rs201231713 & exon 6 & GG: 101 (90.2\%) & GG: 198 (99\%) \\
\hline \multirow[t]{2}{*}{ p.Arg272Gln } & & & GA: 9 (8.0\%) & GA: 2 (1\%) \\
\hline & & & AA: 2 (1.8\%) & AA: $0(0 \%)$ \\
\hline g. $30098022 \mathrm{G}>\mathrm{A}$ & rs200310768 & intron 7 & CC: 109 (97.3\%) & CC: 194 (97\%) \\
\hline \multirow[t]{2}{*}{ c. $914-6 C>T$} & & & CT: 3 (2.7\%) & CT: 6 (3\%) \\
\hline & & & T: 0 (0\%) & Tा: 0 (0\%) \\
\hline g. $30097630 C>T$ & rs2289292 & exon 9 & GG: 32 (28.6\%) & GG: 67 (33.5\%) \\
\hline \multirow[t]{2}{*}{ p.Pro409= } & & & GA: 55 (49.1\%) & GA: 95 (47.5\%) \\
\hline & & & AA: 25 (22.3\%) & AA: 38 (19\%) \\
\hline
\end{tabular}

The splice site mutation and the rare variants indicated in bold.

a variations presented according to genomic reference sequence (g.) NC_000016.9, coding DNA reference sequence (c.) NM_004608.3 and/or protein reference sequence (p.) NP_004599.2, Genome Build 37.3, dbSNP [52].

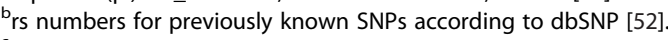

${ }^{c}$ number of genotypes reported as: reference allele/reference allele; reference allele/alternative allele; alternative allele/alternative allele.

from one of the patients with the mutation. Several PCR products were obtained, indicating that several mRNA transcripts are present, but the sizes of the products did not differ in patient and control samples. The reason for this is most likely that very little or none of the mutated transcript is transcribed. Two patients were homozygous for both the exon 4 and the exon 6 variant of TBX6, ten patients were heterozygous for both, and three patients had the exon 4 variant in a heterozygous state. Both variants are situated within the conserved T-box region and the prediction programs indicate that the variants have an effect also on the protein level. We therefore believe that these variants together with other variations have a role in the multifactorial etiology of MA. However, to finally determine the nature of the TBX6 splice site mutation and of the rare homozygous variants in ex 4 and 6 of the gene, in vitro functional studies are needed.

TBX6 has been suggested to associate with congenital scoliosis in the Chinese Han population [56]. Interestingly, vertebral changes giving rise to e.g. scoliosis, are commonly found in patients with MA. Recently, a missense mutation in the last codon of the TBX6 transcript was observed in a Macedonian family with the autosomal dominant form of spondylocostal dysostosis (SCD), characterized by segmentation defects of the vertebrae [57]. The affected individuals were all males and therefore there is no data about the effect of the TBX6 mutation on the development of the female urogenital tract. The family had also experienced six infant deaths (one girl, five boys) of unknown cause without further phenotype data $[57,58]$. Mouse knock-out studies have shown that $T b x 6$ is important for segmentation of the somites in the paraxial mesoderm [59] and for left/right patterning [60]. White and coworkers have shown that Tbx6 interacts with the Notch-ligand delta-like 1 (Dll1) [36], a component in the Notch pathway. Also WNT signaling, acting upstream of $T b x 6$, has been shown to regulate Dll1 activity [61]. Both Notch and WNT signalling are import in the so called segmentation clock, cyclic expression of genes under which each somite is 


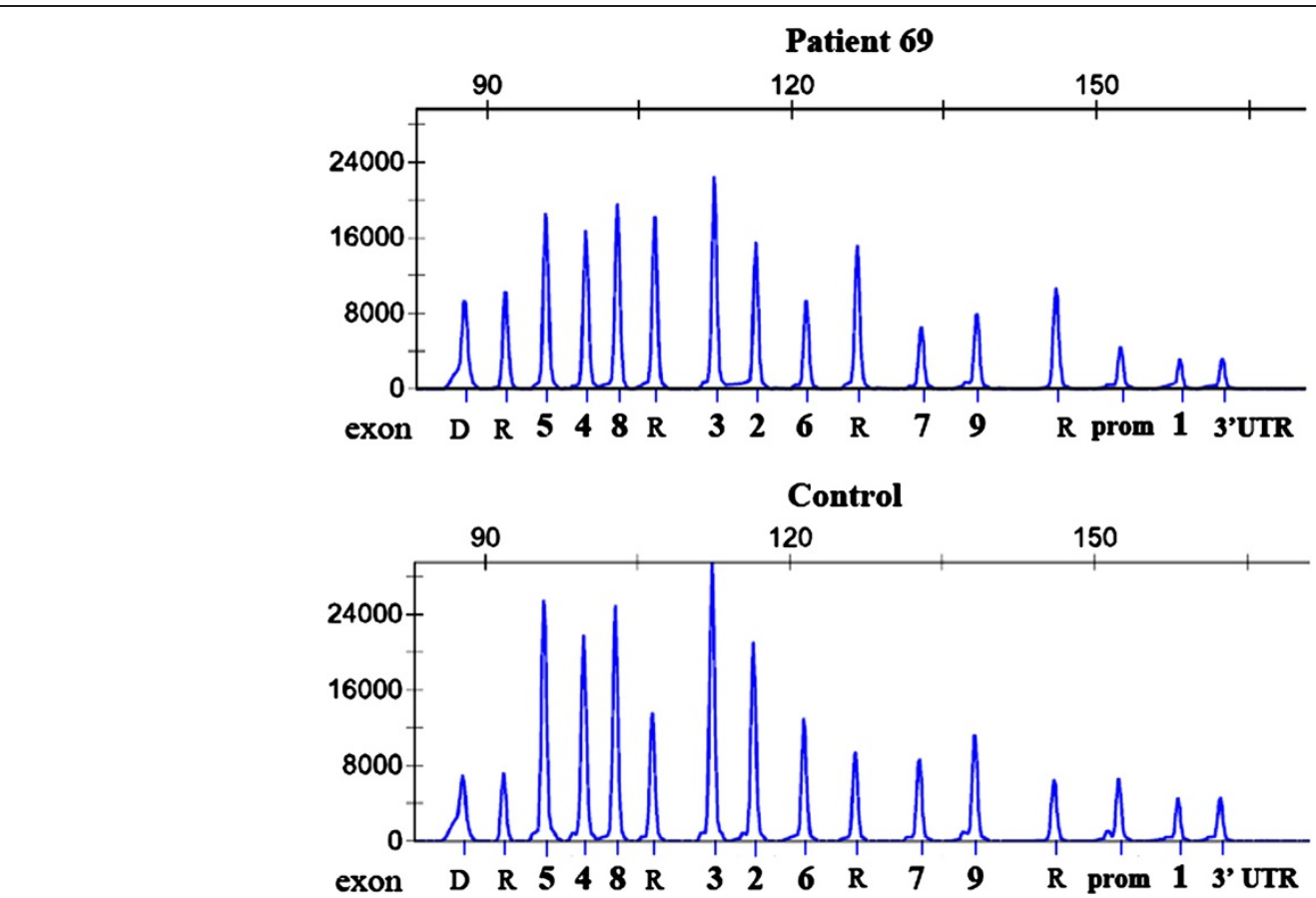

Figure 3 Detection of TBX6 deletions by multiplex ligation probe amplification (MLPA). A $30 \%$ reduction in peak size of the TBX6-specific probes in patient (above) compared to control sample (below). Each exon of TBX6 is indicated by its corresponding number (in bold), prom = promotor, $3^{\prime} U T R=3^{\prime}$ untranscribed region, $D=$ a quality control fragment, and $R=$ four reference probes.

formed from the presomitic mesoderm [62]. It is conceivable that a similar segmentation clock could operate in the segmentation of Müllerian ducts to form upper vagina, uterus and Fallopian tubes.

A spontaneous mouse model for $T b x 6$ is the homozygous $\mathrm{Tbx}^{\mathrm{rv}}$ (rib-vertebrae). It is caused by an insertion in the Tbx6 promotor upstream of the transcriptional start site resulting in a hypomorphic allele and reduced transcript expression [63]. The mutation affects somite formation and patterning featured as malformations of the axial skeleton and fusions of adjacent segments. Interestingly, the model also shows malformations in the

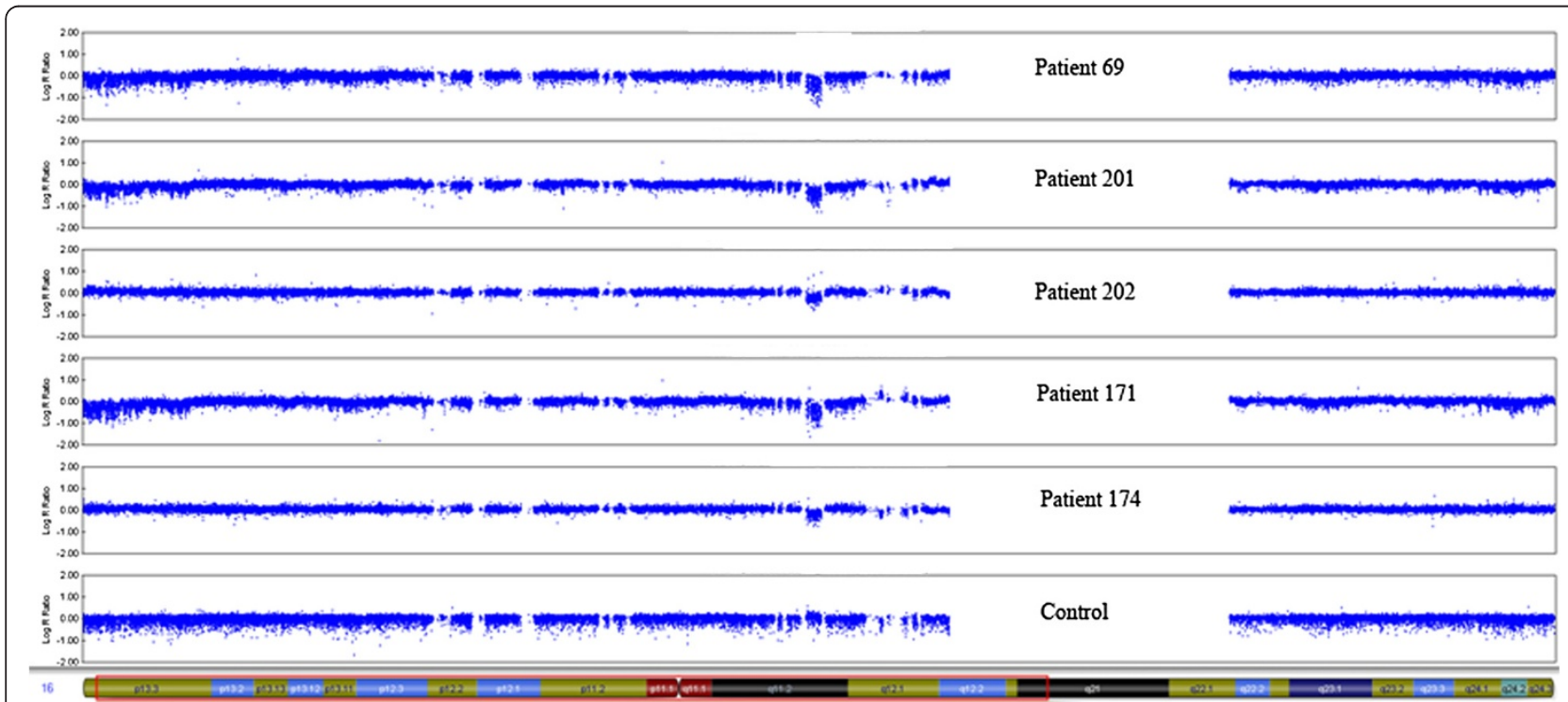

Figure 4 SNP array genotyping confirming the 16p11.2 deletion. Five MA patients were confirmed with the 16p11.2 deletion using HumanOmni2.5-8 v1.0, Illumina. The patient samples are here shown together with a normal control sample (Genome Viewer, GenomeStudio V2011.1, Illumina). 


\section{A}

control

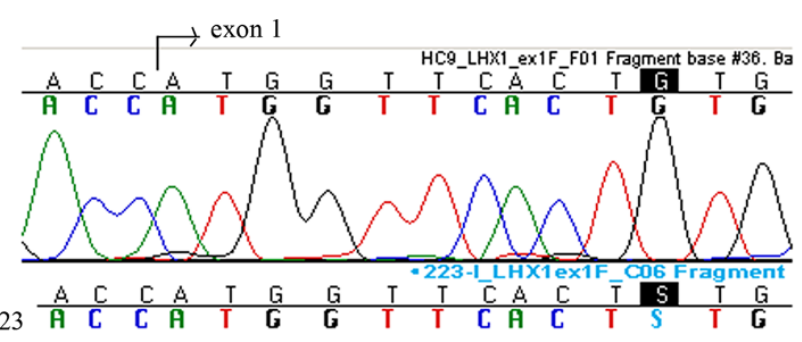

patient 223

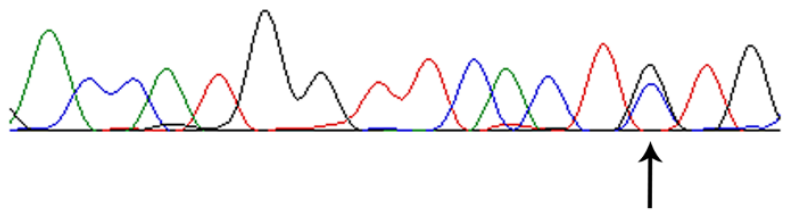

\section{B}

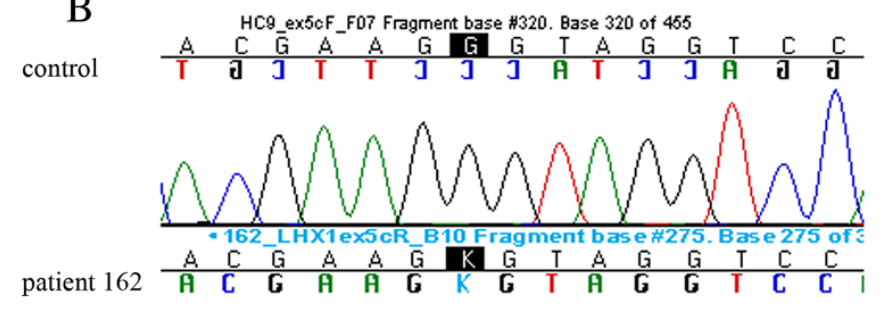

patient 237

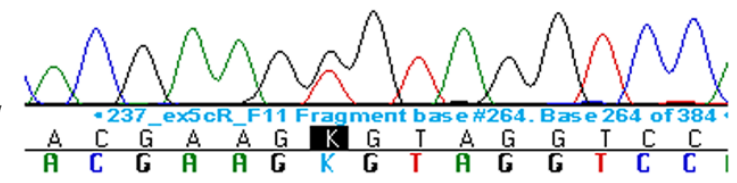

patient 97
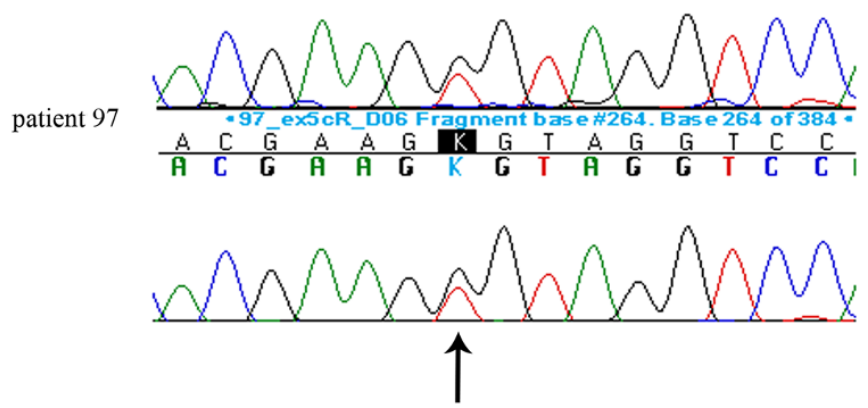

C

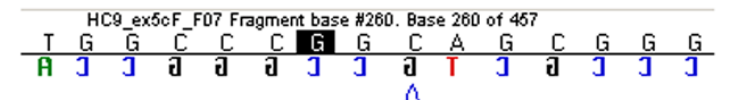

control

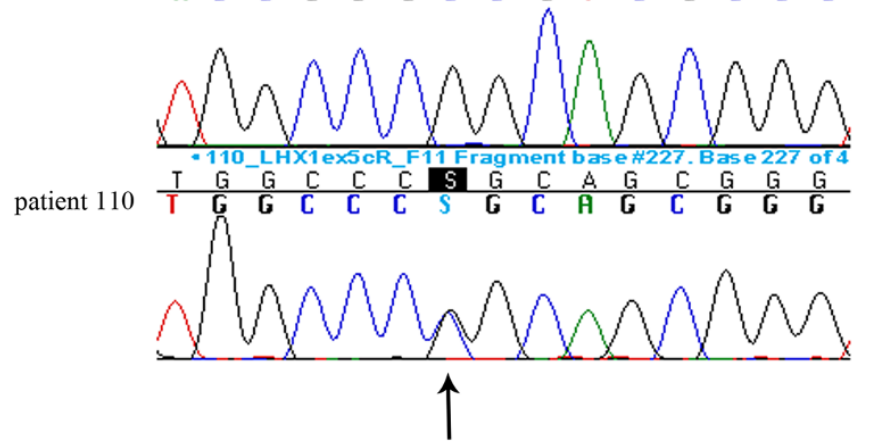

Figure 5 Three novel $L H X 1$ variants found in five MA patients. Three novel $L H X 1$ missense variants found in five MA patients. A) The g.35295505G >C (p.Cys4Ser) variant in control and patient 223, B) the g.35300142C>A (p.Pro312His) in control and patients 162, 237, and 97 and C) the g.35300202C > G (p.Arg332Pro) in control and patient 110. The variations are indicated by arrows. 
Table 3 Variants of $L H X 1$ with allele frequencies

\begin{tabular}{|c|c|c|c|c|}
\hline $\begin{array}{l}\text { Variant }^{\mathrm{a}} \\
\text { Predicted change }\end{array}$ & rs number ${ }^{b}$ & Location in $L H X 1$ & $\begin{array}{l}\text { Genotype of patients }{ }^{d} \\
N=112\end{array}$ & $\begin{array}{l}\text { Genotype of controls } \\
N=180\end{array}$ \\
\hline g.35295505G>C & - & exon 1 & GG: 111 (99.1\%) & GG: 180 (100\%) \\
\hline \multirow[t]{2}{*}{ p.Cys4Ser } & & & GC: 1 (0.9\%) & GC: $0(0 \%)$ \\
\hline & & & CC: $0(0 \%)$ & CC: $0(0 \%)$ \\
\hline g. $35300142 C>A$ & - & exon 5 & CC: 109 (97.3\%) & CC: $180(100 \%)$ \\
\hline \multirow[t]{2}{*}{ p.Pro312His } & & & CA: 3 (2.7\%) & CA: $0(0 \%)$ \\
\hline & & & AA: 0 (0\%) & AA: $0(0 \%)$ \\
\hline g. $35300202 C>G$ & TMP_ESP_17_35300202 & exon 5 & CC: 111 (99.1\%) & CC: $180(100 \%)$ \\
\hline \multirow[t]{2}{*}{ p.Arg332Pro } & & & CG: 1 (0.9\%) & CG: 0 (0\%) \\
\hline & & & GG: $0(0 \%)$ & GG: $0(0 \%)$ \\
\hline
\end{tabular}

${ }^{a}$ variations presented according to genomic reference sequence (g.) NC_000017.10, coding DNA reference sequence (c.) NM_005568.3 and/or protein reference sequence (p.) NP 005559.2, Genome Build 37.3, dbSNP [52].

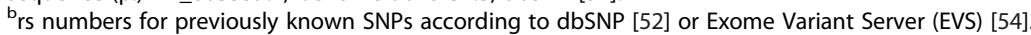

cone allele of 12783 reported in EVS [54].

${ }^{d}$ number of genotypes reported as: reference allele/reference allele; reference allele/alternative allele; alternative allele/alternative allele.

renal and urinary system e.g. with reported single kidney and in the reproductive system with reduced female fertility. Unfortunately, no detailed information is available on the status of the reproductive tract or on why the female mice are reported as poor breeders [64]. However, the $\mathrm{Tbx}^{\mathrm{rv}}$ has phenotypic similarities with MURCS, as the phenotype includes skeletal and renal malformations. In addition, if the reduced fertility is caused by defects in the reproductive tract, the mouse model would be of interest for functional studies in MA.

Previous candidate gene studies of $L H X 1$ residing in the $17 \mathrm{q} 12$ deletion region revealed two MA patients with heterozygous mutations $[17,18]$. The gene had been suggested as a strong candidate for mutation screening based on studies in mice [19] showing that $\lim 1$, which is $99.5 \%$ homologous to the human $L H X 1$ gene [65], is

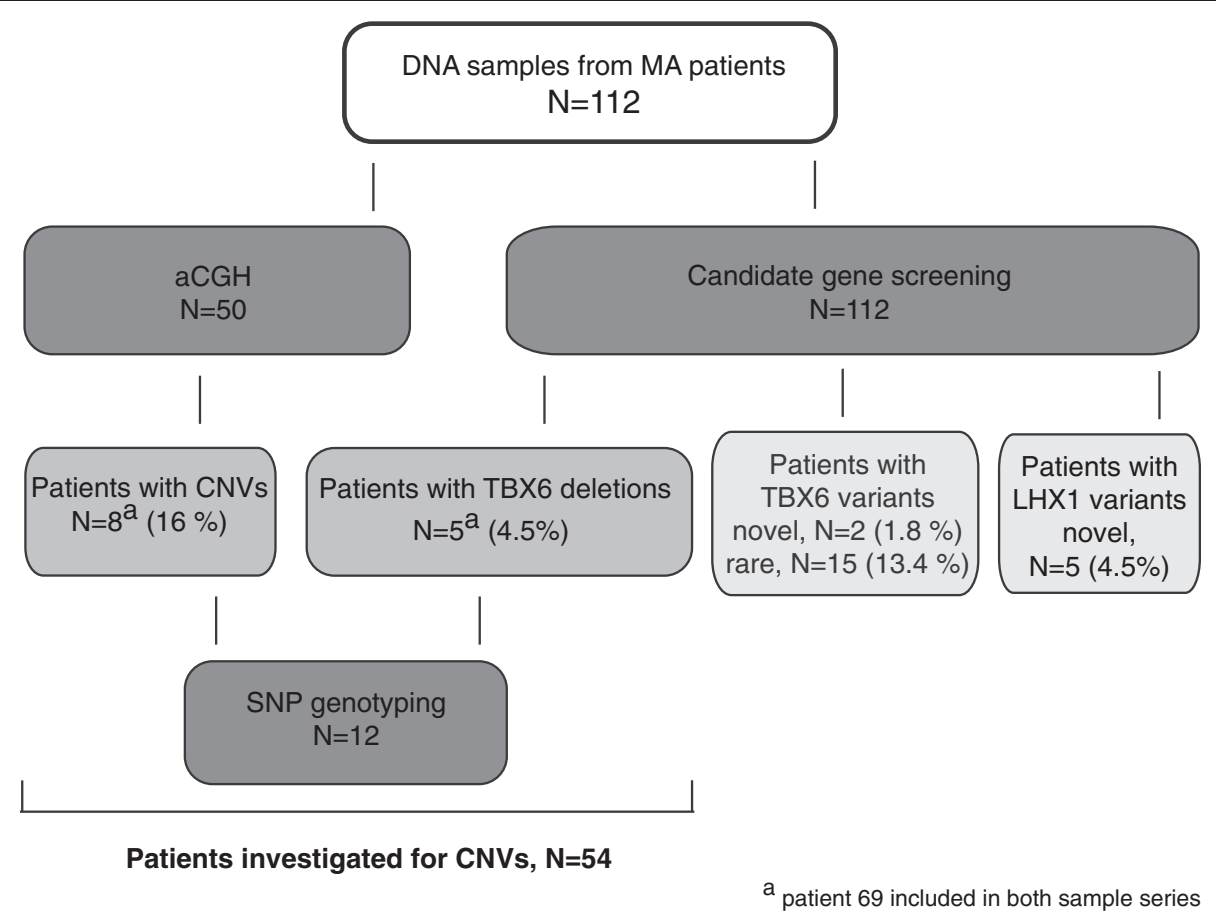

Figure 6 Flow chart summarizing main results and methods. A flow chart summarizing the main results and methods used in the study, including number of patient samples investigated by each of the methods. 
expressed in the epithelium of the developing Müllerian duct during its formation. Female lim1-null mice present normal ovaries but completely lack all derivatives of the Müllerian ducts (oviducts, uterus, cervix and the upper region of the vagina), thereby resembling the total MA phenotype. Therefore, we performed sequencing of LHX1 in our patient cohort and found three novel missense variants in five MA patients (four Finnish and one foreign). The in silico prediction programs indicate that the exon 1 variant is deleterious, while the data for the other two are discrepant. Further studies are needed to define their role in the development of MA. The patient with the exon 1 variant (Cys4Ser) had total MA. Interestingly, one patient with the exon 5 variant (Pro312His) was also homozygous for both rare TBX6 variants (rs56098093 and rs201231713). Another patient with the same LHX1 exon 5 variant was heterozygous for both rare TBX6 variants. Furthermore, the other patient homozygous for both rare TBX6 variants was also identified with a 11q13.4 deletion.

We also identified nine different CNVs in 12 patients (10.7\%) using aCGH and SNP genotyping. Seven of the CNVs are novel (five deletions found in one patient each and two duplications found in the same patient) reported here for the first time in association with MA, and have not been documented in normal controls (DGV) [38]. Nevertheless, we cannot conclude if they have a role in the development of MA. However, the genes located within these CNVs are possible candidate genes for further studies. Two CNVs, namely deletions in 16p11.2 and 17q12, have previously been described in four [29] and eight [17,27-29] MA patients, respectively. We found the 16p11.2 deletion in five patients and the $17 \mathrm{q} 12$ deletion in one patient, adding the total number of MA patients to nine for both deletions. Although the number of patients identified with the deletions is low, they have to date been identified in MA patients originating in two and five different populations, respectively, and therefore they are likely to be relevant for the development of MA.

The 16p11.2 region is prone to rearrangements and $\mathrm{CNVs}$ in the region have previously been associated with different clinical phenotypes [31-33,66], [35], [34]. Bijlsma and coworkers sequenced the coding regions of ALDOA, TBX6 and SPN in four patients with 16p11.2 deletion and mild mental retardation. No mutations were found and they concluded that CNVs of $16 \mathrm{p} 11.2$ are associated with variable phenotypes [67]. In our study, five MA patients showed the deletion. Three of these had skeletal findings including scoliosis and minor vertebral defects, which are known symptoms of MA. In addition, one patient had an unexplained weight gain of $32 \mathrm{~kg}$ within 2 years and another had experienced seizures of unknown cause. Because the 16p11.2 region is large and includes many genes, it is reasonable to assume that several phenotypes, including MA, may be associated with this deletion.

\section{Conclusions}

Taken together, our findings suggest that both TBX6 and LHX1 participate in the control of the development of the female reproductive tract. While the number of mutations so far identified in these two genes is low, more mutations are likely to be found when extending the mutation screening to other populations and to embrace the promotor regions, intronic sequences and the $5^{\prime}$ and 3 ' UTR regions of the genes. Our results also strengthen the previous finding that deletions in 16p11.2 and 17q12 are associated with MA. Furthermore, the results support the hypothesis that MA indeed is a complex trait as demonstrated by the finding that four of our patients were shown to carry variants in both TBX6 and $L H X 1$ or a CNV in combination with TBX6 variants. While our findings on TBX6 need to be confirmed in independent patient cohorts, it is equally important that further genes in the deleted regions are studied for an association with MA. Likewise, functional studies of the identified genes will enhance the understanding of how the Müllerian derivatives are formed during normal embryogenesis and how and why the development is disrupted to result in Müllerian agenesis, the congenital abnormality, which so profoundly affects the life of young females.

\section{Additional file}

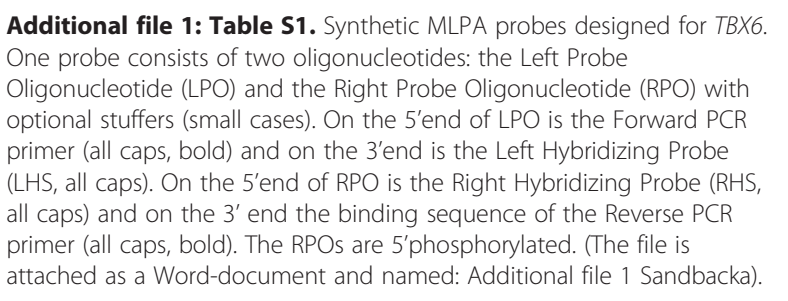

\section{Competing interests}

The authors declare that they have no competing interests.

\section{Authors' contributions}

MS designed and performed the majority of the experiments, performed data analysis and wrote the manuscript. EF designed and performed aCGH, analyzed the data and contributed to writing the manuscript. $\mathrm{MH}, \mathrm{VJ}$ and LMP contributed to recruitment and examination of patients, clinical data collection, and critically revised the manuscript. CR analyzed aCGH data and contributed in writing the manuscript. $\mathrm{HL}$ and $\mathrm{KA}$ designed the study and contributed in writing the manuscript. KA is the guarantor of the study. All authors have seen and approved the final version.

\section{Acknowledgements}

Professors Aarno Palotie, Markus Perola and Samuli Ripatti as well as AnttiPekka Sarin, Richard Durbin and Maija Wessman are acknowledged for kindly sharing cohort sequence data, supported through funds from the Wellcome Trust (grant number WT089062), the Academy of Finland (200923, 00213), the ENGAGE project and grant agreement HEALTH-F4-2007-201413. Professor 
Päivi Peltomäki and Annette Gylling are acknowledged for sharing their inspiring thoughts. The genotyping of SNP markers was performed by the Technology Centre, Institute for Molecular Medicine Finland (FIMM), University of Helsinki, Finland. The study has been funded by Samfundet Folkhälsan, Victoria Foundation, Finska Läkaresällskapet Foundation, Medicinska understödsföreningen Liv och Hälsa Foundation, University of Helsinki and by Finnish State Funds.

\section{Author details}

${ }^{1}$ Folkhälsan Institute of Genetics, Helsinki, Finland. ${ }^{2}$ Department of Medical Genetics, Haartman Institute, University of Helsinki, Helsinki, Finland. ${ }^{3}$ Department of Obstetrics and Gynecology, Helsinki University Central Hospital, Helsinki, Finland. ${ }^{4}$ Department of Genetics and Evolutionary Biology, Institute of Biosciences, University of São Paulo, São Paulo, Brazil. ${ }^{5}$ Department of Obstetrics and Gynecology, University of Turku, Turku, Finland. ${ }^{6}$ Department of Obstetrics and Gynecology, Oulu University Hospital, Oulu, Finland. 'Department of Clinical Genetics, HUSLAB, Helsinki University Central Hospital, Helsinki, Finland.

Received: 25 April 2013 Accepted: 14 August 2013

Published: 16 August 2013

\section{References}

1. Griffin JE, Edwards C, Madden JD, Harrod MJ, Wilson JD: Congenital absence of the vagina. The Mayer-Rokitansky-Kuster-Hauser syndrome. Ann Intern Med 1976, 2:224-236.

2. Aittomäki $K$, Eroila $H$, Kajanoja P: A population-based study of the incidence of Müllerian aplasia in Finland. Fertil Steril 2001, 3:624-625.

3. Kobayashi A, Behringer RR: Developmental genetics of the female reproductive tract in mammals. Nat Rev Genet 2003, 12:969-980.

4. Spencer TE, Dunlap KA, Filant J: Comparative developmental biology of the uterus: insights into mechanisms and developmental disruption. Mol Cell Endocrinol 2012, 1-2:34-53.

5. Resendes BL, Sohn SH, Stelling JR, Tineo R, Davis AJ, Gray MR, Reindollar RH: Role for anti-Mullerian hormone in congenital absence of the uterus and vagina. Am J Med Genet 2001, 2:129-136.

6. Zenteno JC, Carranza-Lira S, Kofman-Alfaro S: Molecular analysis of the anti-Mullerian hormone, the anti-Mullerian hormone receptor, and galactose-1-phosphate uridyl transferase genes in patients with the Mayer-Rokitansky-Kuster-Hauser syndrome. Arch Gynecol Obstet 2004, 4:270-273.

7. Oppelt P, Strissel PL, Kellermann A, Seeber S, Humeny A, Beckmann MW, Strick R: DNA sequence variations of the entire anti-Mullerian hormone (AMH) gene promoter and $\mathrm{AMH}$ protein expression in patients with the Mayer-Rokitanski-Kuster-Hauser syndrome. Hum Reprod 2005, 1:149-157.

8. Timmreck LS, Pan HA, Reindollar RH, Gray MR: WNT7A mutations in patients with Mullerian duct abnormalities. J Pediatr Adolesc Gynecol 2003, 4:217-221.

9. Lalwani $\mathrm{S}, \mathrm{Wu} H \mathrm{HH}$, Reindollar RH, Gray MR: HOXA10 mutations in congenital absence of uterus and vagina. Fertil Steril 2008, 2:325-330.

10. Karnis MF, Stelling JR, Lalwani SI, Bhagavath B, Pan HA, Davis AJ, Reindollar $\mathrm{RH}$, Gray MR: Mutation analysis of the HOXA13 gene in patients with congenital absence of the uterus and vagina. J Soc Gynecol Invest 2000, 7:172A.

11. Dang Y, Qin Y, Tang R, Mu Y, Li G, Xia M, Chen ZJ: Variants of the WNT7A gene in Chinese patients with mullerian duct abnormalities. Fertil Steril 2012, 2:391-394.

12. Ekici $A B$, Strissel PL, Oppelt PG, Renner SP, Brucker S, Beckmann MW, Strick R: HOXA10 and HOXA13 sequence variations in human female genital malformations including congenital absence of the uterus and vagina. Gene 2013, 2:267-272.

13. Biason-Lauber A, Konrad D, Navratil F, Schoenle EJ: A WNT4 mutation associated with Müllerian-duct regression and virilization in a 46, XX woman. N Engl J Med 2004, 8:792-798.

14. Biason-Lauber A, De Filippo G, Konrad D, Scarano G, Nazzaro A, Schoenle EJ: WNT4 deficiency-a clinical phenotype distinct from the classic MayerRokitansky-Kuster-Hauser syndrome: a case report. Hum Reprod 2007, 1:224-229.

15. Philibert P, Biason-Lauber A, Rouzier R, Pienkowski C, Paris F, Konrad D, Schoenle $E$, Sultan C: Identification and functional analysis of a new WNT4 gene mutation among 28 adolescent girls with primary amenorrhea and mullerian duct abnormalities: a French collaborative study. J Clin Endocrinol Metab 2008, 3:895-900.

16. Philibert $P$, Biason-Lauber A, Gueorguieva I, Stuckens C, Pienkowski C, Lebon-Labich B, Paris F, Sultan C: Molecular analysis of WNT4 gene in four adolescent girls with mullerian duct abnormality and hyperandrogenism (atypical Mayer-Rokitansky-Kuster-Hauser syndrome). Fertil Steril 2011, 8:2683-2686.

17. Ledig S, Schippert C, Strick R, Beckmann MW, Oppelt PG, Wieacker P: Recurrent aberrations identified by array-CGH in patients with MayerRokitansky-Kuster-Hauser syndrome. Fertil Steril 2011, 5:1589-1594.

18. Ledig S, Brucker S, Barresi G, Schomburg J, Rall K, Wieacker P: Frame shift mutation of LHX1 is associated with Mayer-Rokitansky-Kuster-Hauser (MRKH) syndrome. Hum Reprod 2012, 9:2872-2875.

19. Kobayashi A, Shawlot W, Kania A, Behringer RR: Requirement of Lim1 for female reproductive tract development. Development 2004, 131:539-549.

20. Cheroki C, Krepischi-Santos AC, Rosenberg C, Jehee FS, Mingroni-Netto RC, Pavanello Filho I, Zanforlin Filho S, Kim CA, Bagnoli VR, Mendonca BB, Szuhai K, Otto PA: Report of a del22q11 in a patient with MayerRokitansky-Küster-Hauser (MRKH) anomaly and exclusion of WNT-4, RARgamma, and RXR-alpha as major genes determining MRKH anomaly in a study of 25 affected women. Am J Med Genet A 2006, 12:1339-1342.

21. Drummond JB, Rezende CF, Peixoto FC, Carvalho JS, Reis FM, De Marco L: Molecular analysis of the beta-catenin gene in patients with the MayerRokitansky-Kuster-Hauser syndrome. J Assist Reprod Genet 2008, 11-12:511-514

22. Ma J, Qin Y, Liu W, Duan H, Xia M, Chen ZJ: Analysis of PBX1 mutations in 192 Chinese women with Mullerian duct abnormalities. Fertil Steril 2011, 8:2615-2617.

23. Wang $P$, Zhao H, Sun M, Li Y, Chen ZJ: PAX2 in 192 Chinese women with Mullerian duct abnormalities: mutation analysis. Reprod Biomed Online 2012, 2:219-222

24. Ravel C, Bashamboo A, Bignon-Topalovic J, Siffroi JP, McElreavey K, Darai E: Polymorphisms in DLGH1 and LAMC1 in Mayer-Rokitansky-Kuster-Hauser syndrome. Reprod Biomed Online 2012, 4:462-465.

25. Bendavid C, Pasquier L, Watrin T, Morcel K, Lucas J, Gicquel I, Dubourg C, Henry C, David V, Odent S, Leveque J, Pellerin I, Guerrier D: Phenotypic variability of a 4 q34->qter inherited deletion: MRKH syndrome in the daughter, cardiac defect and Fallopian tube cancer in the mother. Eur J Med Genet 2007, 1:66-72.

26. Sundaram UT, McDonald-McGinn DM, Huff D, Emanuel BS, Zackai EH, Driscoll DA, Bodurtha J: Primary amenorrhea and absent uterus in the 22q11.2 deletion syndrome. Am J Med Genet A 2007, 17:2016-2018.

27. Cheroki C, Krepischi-Santos AC, Szuhai K, Brenner V, Kim CA, Otto PA, Rosenberg C: Genomic imbalances associated with mullerian aplasia. J Med Genet 2008, 4:228-232.

28. Bernardini L, Gimelli S, Gervasini C, Carella M, Baban A, Frontino G, Barbano G, Divizia MT, Fedele L, Novelli A, Bena F, Lalatta F, Miozzo M, Dallapiccola B: Recurrent microdeletion at $17 q 12$ as a cause of Mayer-Rokitansky-Kuster-Hauser (MRKH) syndrome: two case reports. Orphanet J Rare Dis 2009, 4:25.

29. Nik-Zainal S, Strick R, Storer M, Huang N, Rad R, Willatt L, Fitzgerald T, Martin V, Sandford R, Carter NP, Janecke AR, Renner SP, Oppelt PG, Oppelt P, Schulze C, Brucker S, Hurles M, Beckmann MW, Strissel PL, Shaw-Smith C: High incidence of recurrent copy number variants in patients with isolated and syndromic Mullerian aplasia. J Med Genet 2011, 3:197-204.

30. Edghill EL, Bingham C, Ellard S, Hattersley AT: Mutations in hepatocyte nuclear factor-1 beta and their related phenotypes. J Med Genet 2006, 1:84-90.

31. Kumar RA, KaraMohamed S, Sudi J, Conrad DF, Brune C, Badner JA, Gilliam TC, Nowak NJ, Cook EH Jr, Dobyns WB, Christian SL: Recurrent 16 p11.2 microdeletions in autism. Hum Mol Genet 2008, 4:628-638.

32. Weiss LA, Shen Y, Korn JM, Arking DE, Miller DT, Fossdal R, Saemundsen E, Stefansson H, Ferreira MA, Green T, Platt OS, Ruderfer DM, Walsh CA, Altshuler D, Chakravarti A, Tanzi RE, Stefansson K, Santangelo SL, Gusella JF, Sklar P, Wu BL, Daly MJ: Autism Consortium: Association between microdeletion and microduplication at 16p11.2 and autism. N Engl J Med 2008, 7:667-675.

33. Rosenfeld JA, Coppinger J, Bejjani BA, Girirajan S, Eichler EE, Shaffer LG, Ballif $B C$ : Speech delays and behavioral problems are the predominant features in individuals with developmental delays and 16p11.2 microdeletions and microduplications. J Neurodev Disord 2010, 1:26-38. 
34. Walters RG, Jacquemont $S$, Valsesia A, de Smith AJ, Martinet $D$, Andersson J, Falchi M, Chen F, Andrieux J, Lobbens S, Delobel B, Stutzmann F, El-Sayed Moustafa JS, Chevre JC, Lecoeur C, Vatin V, Bouquillon S, Buxton JL, Boute O, Holder-Espinasse M, Cuisset JM, Lemaitre MP, Ambresin AE, Brioschi A, Gaillard M, Giusti V, Fellmann F, Ferrarini A, Hadjikhani N, Campion D: A new highly penetrant form of obesity due to deletions on chromosome 16p11.2. Nature 2010, 7281:671-675.

35. McCarthy SE, Makarov V, Kirov G, Addington AM, McClellan J, Yoon S, Perkins DO, Dickel DE, Kusenda M, Krastoshevsky O, Krause V, Kumar RA, Grozeva D, Malhotra D, Walsh T, Zackai EH, Kaplan P, Ganesh J, Krantz ID, Spinner NB, Roccanova P, Bhandari A, Pavon K, Lakshmi B, Leotta A, Kendall J, Lee YH, Vacic V, Gary S, lakoucheva LM, et al: Microduplications of 16p11.2 are associated with schizophrenia. Nat Genet 2009, 11:1223-1227.

36. White PH, Farkas DR, McFadden EE, Chapman DL: Defective somite patterning in mouse embryos with reduced levels of Tbx6. Development 2003, 8:1681-1690.

37. Sandbacka M, Halttunen M, Jokimaa V, Aittomaki K, Laivuori H: Evaluation of SHOX copy number variations in patients with Mullerian aplasia. Orphanet J Rare Dis 2011, 6:53.

38. Database of Genomic Variants. [http://projects.tcag.ca/variation/]

39. Ensembl. [http://www.ensembl.org/index.html]

40. CpG Plot. http://www.ebi.ac.uk/Tools/seqstats/emboss_cpgplot/

41. CpG Island Searcher. [http://www.uscnorris.com/cpgislands2/cpg.aspx]

42. UCSC Genome Browser. [http://www.genome.ucsc.edu/cgi-bin/hgGateway]

43. Raw-Probe Version 0.15ß. http://www.mlpa.com/WebForms/WebFormMain. aspx?Tag=zjCZBtdOUyAt3KF3EwRZhAPz9QEm7akikAm7AOEGw1vtZvffaZPOi Sig8ugel7Yd

44. Mfold. [http://mfold.rna.albany.edu/]

45. ExonPrimer. [http://ihg.gsf.de/ihg/ExonPrimer.html]

46. Primer3 v. 0.4.0. [http://frodo.wi.mit.edu/primer3/input.htm]

47. Schwarz JM, Rodelsperger C, Schuelke M, Seelow D: MutationTaster evaluates disease-causing potential of sequence alterations. Nat Methods 2010, 8:575-576.

48. PON-P. [http://bioinf.uta.fi/PON-P/]

49. SpliceMan. [http://fairbrother.biomed.brown.edu/spliceman/index.cgi]

50. SplicePort. http://spliceport.cbcb.umd.edu/SplicingAnalyser.html

51. Human Splicing Finder. [http://www.umd.be/HSF/]

52. dbSNP. [http://www.ncbi.n/m.nih.gov/projects/SNP/].

53. 1000 Genomes. [http://browser.1000genomes.org/index.html]

54. Exome Variant Server. [http://evs.gs.washington.edu/EVS/]

55. Yi CH, Terrett JA, Li QY, Ellington K, Packham EA, Armstrong-Buisseret L, McClure $P$, Slingsby T, Brook JD: Identification, mapping, and phylogenomic analysis of four new human members of the T-box gene family: EOMES, TBX6, TBX18, and TBX19. Genomics 1999, 1:10-20.

56. Fei Q, Wu Z, Wang H, Zhou X, Wang N, Ding Y, Wang Y, Qiu G: The association analysis of TBX6 polymorphism with susceptibility to congenital scoliosis in a Chinese Han population. Spine (Phila Pa.1976) 2010, 9:983-988.

57. Sparrow DB, Mclnerney-Leo A, Gucev ZS, Gardiner B, Marshall M, Leo PJ, Chapman DL, Tasic V, Shishko A, Brown MA, Duncan EL, Dunwoodie SL: Autosomal dominant spondylocostal dysostosis is caused by mutation in TBX6. Hum Mol Genet 2013, 8:1625-1631.

58. Gucev ZS, Tasic V, Pop-Jordanova N, Sparrow DB, Dunwoodie SL, Ellard S, Young E, Turnpenny PD: Autosomal dominant spondylocostal dysostosis in three generations of a Macedonian family: Negative mutation analysis of DLL3, MESP2, HES7, and LFNG. Am J Med Genet A 2010, 6:1378-1382.

59. Chapman DL, Papaioannou VE: Three neural tubes in mouse embryos with mutations in the T-box gene Tbx6. Nature 1998, 6668:695-697.

60. Hadjantonakis AK, Pisano E, Papaioannou VE: Tbx6 regulates left/right patterning in mouse embryos through effects on nodal cilia and perinodal signaling. PLOS One 2008, 6:e2511.

61. Hofmann M, Schuster-Gossler K, Watabe-Rudolph M, Aulehla A, Herrmann BG, Gossler A: WNT signaling, in synergy with T/TBX6, controls Notch signaling by regulating DII1 expression in the presomitic mesoderm of mouse embryos. Genes Dev 2004, 22:2712-2717.

62. Oginuma M, Niwa Y, Chapman DL, Saga Y: Mesp2 and Tbx6 cooperatively create periodic patterns coupled with the clock machinery during mouse somitogenesis. Development 2008, 15:2555-2562.

63. Watabe-Rudolph M, Schlautmann N, Papaioannou VE, Gossler A: The mouse rib-vertebrae mutation is a hypomorphic Tbx6 allele. Mech Dev 2002, 2:251-256.
64. Theiler K, Varnum DS: Development of rib-vertebrae: a new mutation in the house mouse with accessory caudal duplications. Anat Embryol (Berl) 1985, 1:111-116.

65. GeneCards. [http://www.genecards.org]

66. Fernandez BA, Roberts W, Chung B, Weksberg R, Meyn S, Szatmari P, Joseph-George AM, Mackay S, Whitten K, Noble B, Vardy C, Crosbie V, Luscombe S, Tucker E, Turner L, Marshall CR, Scherer SW: Phenotypic spectrum associated with de novo and inherited deletions and duplications at $16 \mathrm{p} 11.2$ in individuals ascertained for diagnosis of autism spectrum disorder. J Med Genet 2010, 3:195-203.

67. Bijlsma EK, Gijsbers AC, Schuurs-Hoeijmakers JH, van Haeringen A, van de Putte DE F, Anderlid BM, Lundin J, Lapunzina P, Perez Jurado LA, Delle Chiaie B, Loeys B, Menten B, Oostra A, Verhelst H, Amor DJ, Bruno DL, van Essen AJ, Hordijk R, Sikkema-Raddatz B, Verbruggen KT, Jongmans MC, Pfundt R, Reeser HM, Breuning MH, Ruivenkamp CA: Extending the phenotype of recurrent rearrangements of 16p11.2: deletions in mentally retarded patients without autism and in normal individuals. Eur J Med Genet 2009, 2-3:77-87.

doi:10.1186/1750-1172-8-125

Cite this article as: Sandbacka et al:: TBX6, LHX1 and copy number variations in the complex genetics of Müllerian aplasia. Orphanet Journal of Rare Diseases 2013 8:125.

\section{Submit your next manuscript to BioMed Central and take full advantage of:}

- Convenient online submission

- Thorough peer review

- No space constraints or color figure charges

- Immediate publication on acceptance

- Inclusion in PubMed, CAS, Scopus and Google Scholar

- Research which is freely available for redistribution

Submit your manuscript at www.biomedcentral.com/submit
C Biomed Central 